\title{
Transcatheter aortic-valve implantation at the University Hospital Center Zagreb: case report and our first results
}

\author{
Joško Bulum*, Maja Strozzi, Bojan Biočina, Višnja Ivančan \\ University Hospital Center Zagreb, Zagreb, Croatia
}

We present a case of 76-year old woman who underwent surgical mitral valve replacement with mechanical valve prosthesis 15 years ago. Other comorbidities include hypertension, dyslipidemia, atrial fibrillation, bilateral $60 \%$ carotid artery stenosis, cured skin melanoma and ischemic stroke. Ambulatory TTE was performed because of progressive dyspnea and revealed severe aortic stenosis (peak gradient $100 \mathrm{mmHg}$, aortic valve area $0.5 \mathrm{~cm}^{2}$ ) with preserved LV systolic function and normal function of mechanical mitral valve. Coronary angiography was normal. Because of very high surgical risk (EUROSCORE 25.75, STS 20.1) and previous cardiac surgery the patient was referred to our Heart Team for TAVI. Under general anesthesia a self-expanding $26 \mathrm{~mm}$ Medtronic CoreValve was successfully implanted via transfemoral approach. Because of previously implanted mechanical mitral valve the self-expanding valve was highly implanted in order to avoid collision with mechanical prosthesis. Arterial access site was successfully closed with Prostar 10 Fr closure device. Post-procedure TTE showed excellent function of self-expanding valve with peak gradient of $15 \mathrm{mmHg}$ and only trace of aortic regurgitation. The patient is doing well at 6 months follow-up.

A total of 6 TAVI were performed at University Hospital Center Zagreb. The patients were elderly (mean age 82.17;
76-86) and highly symptomatic with very high surgical risk (mean EUROSCORE 14.45, mean STS 19.6²). Elective PCI of LMCA was performed in one patient before the procedure. All patients were implanted with self-expanding Medtronic CoreValves in general anesthesia via transfemoral approach. Artery access sites were successfully closed in all patients with Prostar closure device. In 2 of our patients permanent pacemaker has to be implanted after valve implantation. There was no in-hospital mortality and mean hospital length of stay was 10.33 days (7-13 days). One patient died 2 months after discharge because of gastro-intestinal bleeding.

KEYWORDS: aortic stenosis, mechanical mitral valve prosthesis, transcatheter aortic valve implantation.

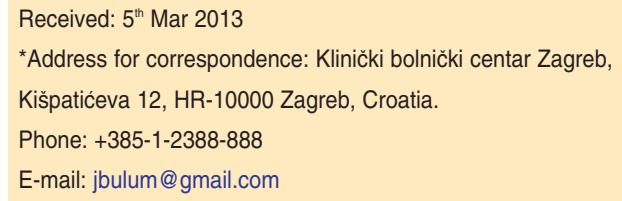

\section{Literature}

1. Vahanian A, Alfieri O, Al-Attar N, Antunes M, Bax J, Cormier B, et al; European Association of Cardio-Thoracic Surgery; European Society of Cardiology; European Association of Percutaneous Cardiovascular Interventions. Transcatheter valve implantation for patients with aortic stenosis: a position statement from the European Association of CardioThoracic Surgery (EACTS) and the European Society of Cardiology (ESC), in collaboration with the European Association of Percutaneous Cardiovascular Interventions (EAPCI). Eur Heart J. 2008;29:1463-70.

2. Leon MB, Smith CR, Mack M, Miller DC, Moses JW, Svensson LG, et al; PARTNER Trial Investigators. Transcatheter aortic-valve implantation for aortic stenosis in patients who cannot undergo surgery. N Engl J Med. 2010;363:1597-607.

3. Ludman. UK Registry, TAVI Facts, Figures and National Registries. EuroPCR 2010, Paris, France.

4. Bekeredjian R, Krumsdorf U, Chorianopoulos E, Kallenbach K, Karck M, Katus HA, et al. Usefulness of percutaneous aortic valve implantation to improve quality of life in patients $>80$ years of age. Am J Cardiol. 2010;106(12):1777-81. 